\title{
POLA KELETAKAN BANGUNAN INDIS DI KOTA GORONTALO
}

\section{LOCATIONAL PATTERN OF INDIES BUILDINGS IN GORONTALO}

\author{
Irfanuddin Wahid Marzuki \\ Balai Arkeologi Manado \\ wd_456@yahoo.co.id
}

\begin{abstract}
Indies buildings in Gorontalo are spread within several areas, namely Ipilo, Biawao, and Tenda. These buildings serve as offices, houses, schools, hotels, religious building, and shop. Research on indies buildings in Gorontalo aims to find its locational pattern and to determine the relationship among those buildings. This research uses descriptive method with an inductive approach. Analysis of the data using the nearest neighbour analysis. The results showed a locational pattern of Indies buildings are clustered around the square. Based on their function, houses, and hotel are clustered, while school and office buildings are randomly located. The relationship between the building relates to the function of each building. Residential and office buildings are located adjacent to the effectiveness. School buildings are spread to facilitate access to people living in all parts of the town. Religious building is located in the center to facilitate access from every direction, and shops are clustered adjacent to the market as the economic center.
\end{abstract}

Keywords: Location pattern, Indis buildings, Relation between the building

\begin{abstract}
ABSTRAK
Bangunan Indis di Kota Gorontalo tersebar di beberapa wilayah, yaitu Kelurahan Ipilo, Biawao, dan Kampung Tenda. Bangunan-bangunan tersebut berfungsi sebagai perkantoran, rumah tinggal, sekolah, hotel, bangunan ibadah, dan pertokoan. Penelitian mengenai pola keletakan bangunan Indis di Gorontalo bertujuan untuk mencari pola keletakan dan hubungan antar bangunan Indis tersebut. Penelitian menggunakan metode deskriptif, dengan pendekatan induktif. Analisis data menggunakan analisis tetangga terdekat (nearest neighbour analysis). Hasil penelitian menunjukkan pola keletakan bangunan Indis di Kota Gorontalo secara umum bersifat mengelompok. Sementara berdasarkan kategori fungsinya, bangunan rumah tinggal dan hotel bersifat mengelompok disekitar lapangan (alun-alun). Bangunan sekolah dan perkantoran bersifat acak. Hubungan antar bangunan berkaitan dengan fungsi dari masing-masing bangunan. Bangunan perumahan dan perkantoran lokasinya berdekatan untuk efektivitas. Bangunan sekolah menyebar supaya dapat dijangkau dari berbagai tempat dan kalangan. Bangunan rumah ibadah di tengah untuk memudahkan mencapainya, dan bangunan pertokoan berdekatan dengan pasar sebagai pusat perekonomian.
\end{abstract}

Kata kunci: Pola keletakan, Bangunan Indis, Hubungan antar bangunan.

Tanggal masuk : 15 Februari 2015

Tanggal diterima : 15 Mei 2015 


\section{PENDAHULUAN}

Kebudayaan

Indis

merupakan perpaduan kebudayaan asli Indonesia dan kebudayaan asing. Awalnya gaya hidup Indis berkembang di Jawa, kemudian berkembang di daerah lain di Indonesia, dengan perpaduan antara kebudayaan Barat dan kebudayaan daerah asli Indonesia. Pada kebudayaan Indis, kebudayaan Belanda lebih dominan dibanding kebudayaan lokal, hal ini dikarenakan pihak Belanda merupakan penguasa sehingga lebih berperan dalam kebudayaan Indis (Soekiman, 2011:19). Penyebutan bangunan Indis di Indonesia digunakan untuk menyebut bangunan-bangunan yang bercorak Eropa/Barat yang dibawa ke Indonesia oleh penjajah Eropa (Wahyuhono dan Hartono, 1997), dan awalnya merupakan rumah tinggal para pejabat pemerintah Hindia Belanda yang memiliki ciri-ciri perpaduan antara bentuk bangunan Belanda dengan rumah tradisional (Gunadi, 1997:1).

Hasil kebudayaan Indis dalam bidang fisik adalah bangunan gedung berarsitektur Indis, yang menggunakan arsitektur campuran dari unsur budaya Barat terutama Belanda dengan budaya lokal. Faktor yang ikut berintegrasi dalam proses perancangan bangunan antara lain : lingkungan, iklim atau cuaca, ketersediaan material, teknik pembuatan, kondisi sosial, politik, ekonomi, kesenian dan agama (Hastati, 2003:14-15). Pemerintah Kolonial Belanda menjadikan arsitektur Indis sebagai standar dalam pembangunan gedunggedung pemerintah dan swasta. Bentuk tersebut banyak ditiru oleh orang kaya terutama pedagang dari etnis tertentu, dengan harapan memperoleh kesan pada status sosial yang sama dengan penguasa dan priyayi (Antariksa, 2010). Berkaitan dengan arsitektur atau bangunan Indis di Kota Gorontalo, dapat dilihat adanya unsur atau pengaruh dari kebudayaan Barat, yaitu : hiasan puncak atap (nockacroterie), penggunaan gable, atau dormer untuk ventilasi pada bagian atap, dinding tembok bata atau beton, denah bangunan segi enam atau segi delapan, pintu dan jendela berukuran tinggi dan besar, pintu berbentuk lengkung setengah lingkaran pada bagian atasnya, konsol besi penyangga model keriting pada tiang, tiang berbentuk bulat (dari kayu ataupun besi), bentuk bangunan yang tinggi, dan lantai ubin (tegel) baik dari semen ataupun kayu (parquet).

Penggunaan tembok bata yang tebal dalam arsitektur Indis dimaksudkan untuk menghindari panas, sedangkan penggunaan ventilasi (gable, dormer, daun pintu dan jendela yang besar) dimaksudkan untuk menangkal udara basah dan lembab. Penggunaan lantai ubin bertujuan untuk sanitasi dan supaya mudah dibersihkan (Soekiman, 2011 : 75). Pembuatan plafon yang tinggi dan

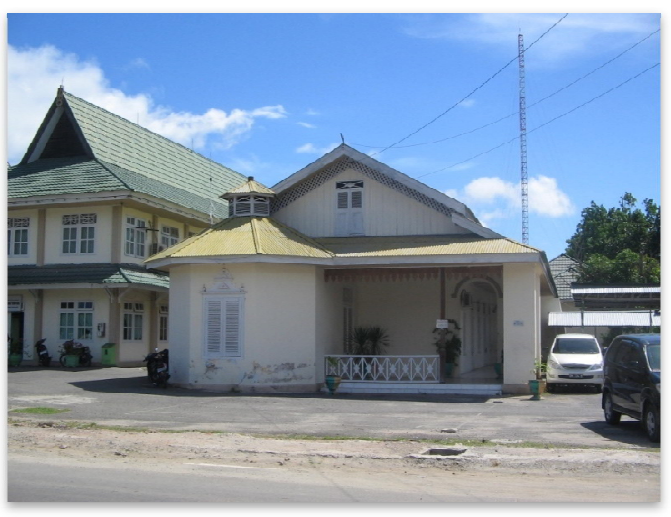

Gambar 1. Salah satu bangunan indis bekas gedung Landbouw yang sekarang menjadi kompleks perkantoran Walikota Gorontalo (dokumentasi Nurachman). 
overstek yang cukup lebar merupakan upaya untuk menyesuaikan dengan lingkungan iklim tropis basah. Dengan membuat plafon yang tinggi, maka volume ruang menjadi lebih besar, sehingga kemungkinan terjadi panas dalam ruang dapat diperkecil. Pembuatan overstek yang lebar selain berfungsi menahan tempias air hujan juga berfungsi sebagai pembayangan dinding yang kena sinar matahari langsung, sehingga ikut mengurangi suhu panas dalam ruangan, akibat radiasi panas matahari tropis yang menyengat (Handinoto, 1986, Wiyatiningsih, 2000:27-28). Penambahan bangunan beranda pada bagian depan dan belakang merupakan adaptasi dari arsitektur lokal Indonesia, karena bangunan asli Belanda tidak ada yang menggunakan beranda karena suhu yang rendah.

Rumah khas Gorontalo
merupakan rumah panggung bertiang tinggi yang terbuat dari bambu atau kayu dengan dinding kayu atau bambu yang belah (tolotahu).Material atap menggunakan ijuk, rumbia atau kayu sirap.Penggunaan tiang tinggi dalam rumah panggung dengan pertimbangan untuk menghindari serangan binatang dan dapat digunakan untuk memelihara ternak atau menyimpan hasil bumi (Yayasan 23 Januari 1982:10). Pengaruh arsitektur barat dalam bangunan Indis di Kota Gorontalo tidak sama pada tiap-tiap bangunan. Ada yang terdapat satu unsur, dua unsur, atau bahkan lebih dari tiga unsur.

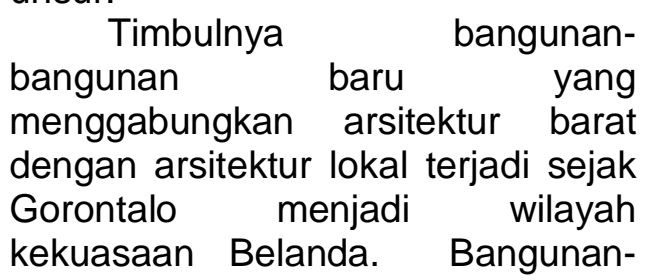

bangunan tersebut berfungsi sebagai kantor pemerintahan, rumah tinggal, asrama militer, rumah ibadah, dan sekolah. Struktur kota berubah seiring dengan bergantinya kekuasaan dari kerajaan menjadi pemerintahan kolonial Belanda. Pada masa pemerintahan Belanda, rakyat tidak diperkenankan tinggal di hutan atau pegunungan, rakyat harus tinggal dalam dusun-dusun yang teratur dan terletak di pinggir jalan besar (Apriyanto, 2006:47).Dari sinilah kemudian tatakota Gorontalo terbentuk sampai sekarang. Berkaitan dengan hal tersebut di atas, permasalahan yang akan dibahas dalam penelitian ini adalah:
a. Bagaimana pola keletakan bangunan Indis dalam perkembangan kota Gorontalo?

b. Bagaimana hubungan antar bangunan-bangunan tersebut dalam satu kawasan perkotaan?

\section{TUJUAN PENELITIAN}

Sesuai dengan rumusan masalah di atas, penelitian tentang Pola Keletakan Bangunan Indis di Kota Gorontalo mempunyai tujuan untuk mencari pola keletakan dan hubungan antar bangunan Indis di Kota Gorontalo dalam satu kawasan perkotaan. Dengan mengetahui pola keletakan dan hubungan tiap bangunan, diharapkan nantinya bisa diketahui faktor yang mempengaruhi penempatan bangunan dalam kawasan tersebut.

\section{LANDASAN TEORI}

Kebudayaan Indis merupakan perpaduan antara kebudayaan Belanda dan kebudayaan lokal Indonesia.Penelitian tentang kebudayaan Indis secara detail dilakukan oleh Djoko Soekiman (1997) dalam disertasinya yang 
berjudul Kebudayaan Indis dan Gaya Hidup Masyarakat Pendukungnya (abad XVIII sampai medio abad XX).Kehadiran kebudayaan Indis meliputi rentang waktu sejak kehadiran bangsa Belanda sampai pertengahan abad ke-20, yaitu kalahnya Belanda oleh Jepang.Hasil kebudayaan Indis yang berhubungan dengan seni karya budaya fisik meliputi seni bangunan, seni rupa, dan seni kerajinan. Seni bangunan Indis pada awalnya berupa bangunan rumah pejabat kolonial, pemerintahan, militer, dan juga tempat ibadah (Soekiman,1997, 2011).

Analisis tetangga terdekat (nearest neighbour analysis) merupakan suatu teknik analisis untuk menentukan pola pemukiman apakah seragam, random atau mengelompok.Analisis tetangga terdekat memerlukan data tentang jarak antar satu pemukiman dengan pemukiman paling dekat/tetangga terdekatnya.Dalam analisis tetangga terdekat, pemukiman dianggap sebagi sebuah titik dalam ruang.Analisis tetangga terdekat sesuai diterapkan dalam wilayah yang tidak ada hambatan-hambatan alamiah yang memisahkan antar pemukiman. Langkah yang dilakukan dalam analisis tetangga terdekat meliputi: a). menentukan batas wilayah, b). merubah pemukiman menjadi titik, c). memberi nomor urut tiap titik untuk mempermudah menganalisa, d). mengukur dan mencatat jarak antar titik terdekat, dan e). menghitung dengan menggunakan rumus yang telah ditentukan. Hasil penghitungan nantinya akan diketahui apakah pola pemukiman tersebut seragam, acak atau mengelompok (Bintarto, 1982).

Pola keletakan tinggalan arkeologi mengacu pada kajian keruangan (spatial archaeology), yang mencari sebaran dan hubungan artefak dalam skala mikro, semi mikro/meso, dan makro. Penelitian mengenai pola hubungan sebaran situs, hubungan antar situs dan factor yang mempengaruhinya merupakan penelitian dalam skala makrao. Kajian arkeologi ruang merupakan kajian penelitian dengan pendekatan dimensi ruang yang dimiliki benda arkeologi sebagai data utamanya. Data utama yang diperlukan dalam arkeologi ruang mencakup tiga hal, yaitu;

a. Keletakan (elemen/unsur) yang mencakup antara lain artefak, raw materials, dan sisa bahan pembuatan; infrastruktur fisik yang mengakomodasi elemen/unsur berupa fitur, struktur, jalan, dan ruang sumber (resource space).

b. Satuan ruang sebagai tempat komunitas manusia beraktivitas (skala makro, mikro dan meso/semi mikro), lingkungan sumberdaya yang berada di dekat mereka atau terkait dengan mereka.

c. Hubungan-hubungan atau interaksi di antara semua unsur-unsur tersebut dalam satuan-satuan ruang yang berbeda skalanya (Tim, 2008:183).

\section{METODE PENELITIAN}

Metode penelitian ini bersifat eksplanatif, yaitu memberikan penjelasan mengenai faktor-faktor yang terdapat di balik suatu gejala dan memberikan penjelasan dengan menerapkan teori tertentu (Tim, 2008:20). Penelitian ini menggunakan penalaran induktif, yang bergerak dari kajian fakta-fakta atau gejala-gejala khusus untuk kemudian disimpulkan sebagai gejala yang bersifat umum atau 
generalisasi empiris (Tanudirdjo, 1989:34). Objek penelitian berupa bangunan-bangunan Indis yang ada di Kota Gorontalo.Lokasi penelitian berada di wilayah kelurahan Biawao, Ipilo dan kelurahan Tenda Kota Gorontalo.Alasan pemilihan lokasi dikarenakan konsentrasi terbanyak tinggalan bangunan Indis berada di wilayah tersebut, di luar wilayah tersebut hampir dikatakan tidak ditemukan adanya bangunan Indis.

Tahap penelitian meliputi pengumpulan data, analisis data, dan kesimpulan. Tahap pengumpulan data dilakukan dengan melalui beberapa tahap, yaitu; studi pustaka, observasi lapangan, dan wawancara.Tahap analisis data dilakukan dengan menggunakan metode analisis tetangga terdekat (nearest neighbour analysis) untuk mencari pola keletakan bangunan dalam satu kawasan.Dalam analisis data dicari pola keletakan bangunan dalam satu kawasan dan hubungan fungsional antar bangunan dalam satu kawasan, tidak hanya segi fisik bangunan, namun juga hubungan lingkungan sekitar situs dan kawasan.

\section{PEMBAHASAN}

\section{A. Pola Keletakan Bangunan Indis}

Bangunan-bangunan Indis di Kota Gorontalo berada di sekitar rumah Dinas Gubernur dan Lapangan Taruna.Pemukiman Belanda berada di sebelah selatan dan barat lapangan.Selain itu juga terdapat di sebelah utara rumah Asisten Residen.Pemukiman Cina dan Arab berada dekat dengan pasar dan pertokoan.Pemukiman pendatang lainnya, seperti Bugis, Sangir, Minahasa, dan Makasar terletak di sekitar pelabuhan. Menurut Ford dalam Rangkuti (2000), kecenderungan politik dan ekonomi dari waktu ke waktu berpengaruh terhadap bentuk atau morfologi kota. Kota-kota pesisir di Indonesia berasal dari pelabuhanpelabuhan dagang yang memperlihatkan aspek ideologi perkotaan dari luar.

Untuk mengetahui pola sebaran bangunan Indis di daerah penelitian, apakah berpola acak, mengelompok, atau teratur dilakukan dengan metode analisis tetangga terdekat (nearest neighbour analysis). Metode analisis tetangga terdekat sesuai untuk daerah-daerah yang antara pemukiman satu dengan yang lain, tidak terdapat hambatan-hambatan alamiah yang berarti. Hambatanhambatan alamiah berarti hambatan yang memisahkan daerah, misalnya sungai atau jurang yang tidak bisa dilewati.Dengan menggunakan analisis tetangga terdekat, perbandingan antara pola pemukiman dapat dilakukan dengan lebih baik (Bintarto, 1982:74-75).

Nilai T/indeks penyebaran tetangga terdekat sendiri diperoleh melalui formula :

$\mathrm{T}=\frac{\mathrm{Ju}}{\mathrm{Jh}}$

Keterangan :

$\mathrm{T}$ : indeks penyebaran tetangga terdekat

$J u$ : jarak rata-rata yang diukur antara

satu titik dengan titik tetangganya yang terdekat

$j h$ :jarak rata-rata yang diperoleh andaikata semua titik mempunyai pola random $=$

jh: $\frac{1}{2 \sqrt{ } p}$

$P:$ kepadatan titik dalam tiap kilometer persegi, yaitu jumlah titik $(\mathrm{N})$ dibagi dengan luas wilayah dalam kilometer persegi (A).

$P: N$

A 
Dari nilai $\mathrm{T}, \quad$ selanjutnya diinterpretasikan dengan Continum Nearest Neighbour Analysis (rangkaian kesatuan tetangga terdekat), sebagai berikut :

Berdasarkan pengamatan di lapangan, luas wilayah daerah penelitian adalah $3,40 \mathrm{~km}^{2}$, dengan jumlah titik sebanyak 30 yang

$$
=\frac{\mathrm{Jh}}{0,11}=0,67
$$

Nilai hasil penghitungan menghasilkan $\mathrm{T}=0,67$, berarti pola keletakan bangunan Indis di Kota Gorontalo adalah mengelompok.

Sedangkan pola keletakan

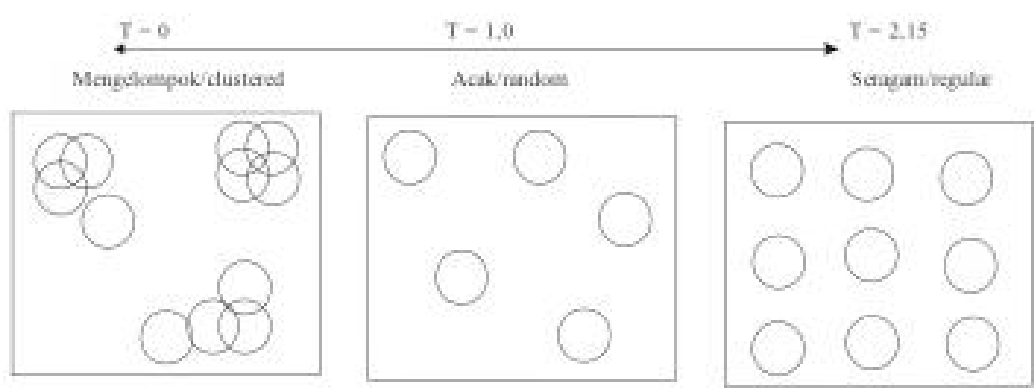

Sumber = Hagget dalam Bintarts dan Hadisumamo( 1982:76)

Gambar 2. Interpretasi dengan Continum Nearest Neighbour Analysis

tersebar di tiga wilayah Kelurahan, yang terbagi menjadi bangunan perkantoran 6 , bangunan rumah tinggal 15, bangunan sekolah 4 , hotel dan tempat pertemuan 3 bangunan, pertokoan dan gereja masing-masing 1 bangunan. Dengan menggunakan analisis tetangga terdekat, maka pola keletakan bangunan Indis di kota Gorontalo dapat dihitung sebagai berikut :

$$
\begin{aligned}
\mathrm{Ju} & =\frac{\text { jumlah jarak }(\square \mathrm{j})}{\text { Jumlah situs }(\square \mathrm{n})} \\
& =\frac{3,24}{30} \\
& =0,11 \\
\mathrm{P} & =\frac{30}{3,4}=8,8 \\
\mathrm{Jh} & =\frac{1}{2 \sqrt{ }} 8,8 \\
& =\frac{1}{2 \times 2}, 96 \\
& =\frac{1}{5,92} \\
& =0,17 \\
\mathrm{~T} & =\underline{\mathrm{u}}
\end{aligned}
$$

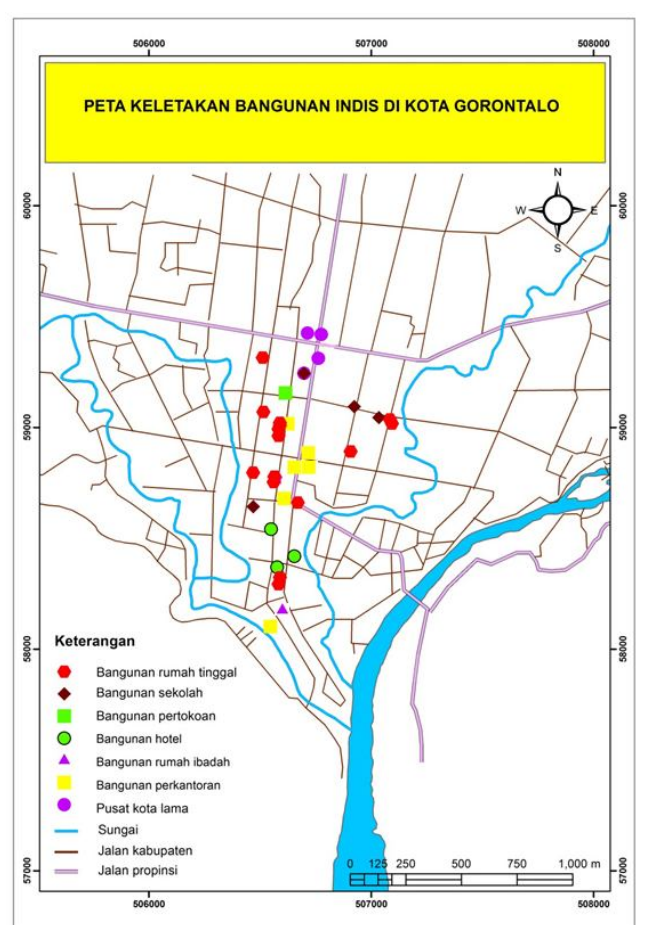

Gambar 3. Peta keletakan bangunan Indis di Kota Gorontalo (digambar Agus T Hascaryo,S.S, S.Si, M.Si, sumber Bappeda Kota Gorontalo).

bangunan Indis di Kota Gorontalo berdasarkan kategori fungsinya 
dapat kelompokkan dalam empat kategori, yaitu :

\section{Bangunan perkantoran}

Bangunan perkantoran terletak di pusat kota, berdekatan dengan bangunan penjara dan tempat tinggal penguasa. Bangunan perkantoran yang terletak di pinggir kota adalah bangunan perusahaan listrik (E. Balloom) yang menyatu dengan pembangkit, kantor, dan tangsi polisi. Alasan penempatan bangunan perkantoran berada di pusat kota, bertujuan agar memudahkan untuk koordinasi antar instansi. Penempatan kantor perusahaan listrik di pinggir kota jauh dari pemukiman supaya masyarakat tidak terganggu dengan suara bising mesin pembangkit listrik. Penempatan kantor polisi kota (stads politie) berada di pusat kota, dekatdengan kantor Asisten Residen dan lapangan (alun-alun), sedangkan kantor polisi lapangan (veld politie) dan tangsi berada di pinggir kota bertujuan untuk menjaga keamanan di pintu masuk kota. Hal ini dikarenakan letak kantor dan tangsi polisi lapangan (veld politie) berada dekat dengan pelabuhan yang merupakan pintu masuk Kota Gorontalo. Bangunan kantor polisi kota (stads politie) saat ini sudah diganti dengan bangunan baru, sebagai kantor urusan SIM Poltabes Gorontalo, sedangkan kantor dan tangsi polisi lapangan (veld politie) berubah menjadi Taman Kanak- Kanak dan Poltabes Gorontalo.

Jarak tetangga terdekat bangunan Indis yang berfungsi sebagai perkantoran di Kota Gorontalo dapat dilihat pada tabel di bawah ini.
Tabel 1. Jarak antar bangunan perkantoran

\begin{tabular}{|c|c|c|}
\hline No & Nama Bangunan & $\begin{array}{c}\text { Jara } \\
\text { k } \\
\text { (m) }\end{array}$ \\
\hline 1 & Asisten Residen-Landbouw & 112 \\
\hline 2 & Landbouw-Kantor Pos & 58 \\
\hline 3 & $\begin{array}{l}\text { Kantor Pos-Rmh Dinas } \\
\text { Kepala ktr Pos }\end{array}$ & 64 \\
\hline 4 & $\begin{array}{l}\text { Rmh dinas Kepala Kantor } \\
\text { Pos }\end{array}$ & 54 \\
\hline 5 & E Balloom-Asisten Residen & 605 \\
\hline 6 & $\begin{array}{l}\text { Kantor Dagang WB } \\
\text { Lendeboer\&co-rmh dinas Ka } \\
\text { Ktr Pos }\end{array}$ & 152 \\
\hline & Total Jarak & 1045 \\
\hline
\end{tabular}

Berdasarkan analisis tetangga terdekat, pola keletakan bangunan Indis yang berfungsi sebagai perkantoran di Kota Gorontalo dapat dihitung sebagai berikut:

$$
\begin{aligned}
\text { Ju } & =\frac{\text { jumlah jarak }(\square \mathrm{i})}{\text { Jumlah situs }(\square \mathrm{n})} \\
& =\frac{1,05}{6} \\
& =0,17 \\
\mathrm{Jh} \quad & =\frac{1}{2 \sqrt{ }} 8,8 \\
& =\frac{1}{2 \times 2,96} \\
& =\frac{1}{5}=0,17
\end{aligned}
$$

Untuk menghitung patokan nilai tetangga terdekat $(\mathrm{T})$ adalah :

$$
\begin{aligned}
& \mathrm{T}=\mathrm{ju} \\
& \mathrm{Jh} \\
& \mathrm{T}=\underline{0,17}=1,0 .
\end{aligned}
$$

Pola keletakan bangunan Indis yang berfungsi sebagai perkantoran tersebut berpola acak, karena nilai $T$ sama dengan 1. 


\section{Bangunan rumah tinggal}

Pemukiman penduduk dikelompokkan menjadi pemukiman Belanda, pemukiman orang asing lain (Cina dan Arab), pemukiman pendatang (Bugis, Makasar, Jawa, Minahasa, dan Sangir), dan pemukiman penduduk pribumi. Pemukiman Belanda berada di pusat Kota, pemukiman orang asing lain berada di sekitar pasar dan pusat perdagangan. Pemukiman pendatang menyebar di sekitar pelabuhan dan pasar, sedangkan pemukiman pribumi menyebar di antara pemukiman-pemukiman tersebut.Pemisahan lokasi pemukiman bagi masyarakat oleh pemerintah Kolonial Belanda didasarkan pada status masyarakat pada waktu itu yang menempatkan orang Eropa dan Timur Asing di atas kelas penduduk pribumi.Peningkatan jumlah pendatang asing mempengaruhi sebaran pemukiman di Kota Gorontalo.Pada awal tahun 1930-an mulai bermunculan rumahrumah batu dari kalangan orang kaya lokal (Amin, 2012:59).

Faktor yang mempengaruhi terjadinya variasi pola sebaran pemukiman antara lain: faktor fisik alami, faktor fisik buatan, dan faktor sosial ekonomis. Faktor-faktor tersebut dapat secara bersamasama ataupun sendiri, namun pola sebaran pemukiman berbeda-beda tergantung pada karakteristik fisik daerah pemukiman tersebut berada.Faktor topografi biasanya memiliki pengaruh yang sangat menentukan dalam pola persebaran permukiman.Daerah dengan topografi datar/landai, merupakan sasaran bertempat tinggal penduduk secara mengelompok (Martono, 1996:36).Topografi Kota Gorontalo secara umum berada pada daerah yang datar/landai dengan ketinggian di bawah $50 \mathrm{mdpl}$. Jarak terdekat antar bangunan rumah tinggal dapat ditampilkan dalam tabel, sebagai berikut:

Tabel 2. Jarak antar bangunan rumah tinggal

\begin{tabular}{|l|l|c|}
\hline No & \multicolumn{1}{|c|}{ Nama Bangunan } & $\begin{array}{c}\text { Jarak } \\
\text { (m) }\end{array}$ \\
\hline \hline 1 & $\begin{array}{l}\text { Rmh Drg Budi Moniaga- rmh } \\
\text { tinggal Sutoyo no.5 }\end{array}$ & 14 \\
\hline 2 & Rmh tinggal Jl. Sutoyo No.5 & 18 \\
\hline 3 & $\begin{array}{l}\text { Rmh tinggal Jl. Sutoyo No. } \\
25-\text { Sutoyo 29 }\end{array}$ & 55 \\
\hline 4 & $\begin{array}{l}\text { Rmh tinggal Jl. Sutoyo No. } \\
29\end{array}$ & 33 \\
\hline 5 & RM Sabar Menanti & 14 \\
\hline 6 & Bridal 21 & 14 \\
\hline 7 & $\begin{array}{l}\text { Swalayan Santika-Sekandar } \\
\text { Liandarise }\end{array}$ & 264 \\
\hline 8 & $\begin{array}{l}\text { Rmh Jl. S Parman No. 15- } \\
\text { Budi Moniaga }\end{array}$ & 98 \\
\hline 9 & $\begin{array}{l}\text { Kantor Dinas Pertambangan } \\
\text { dan Kehutanan-Sweet Home }\end{array}$ & 34 \\
\hline 10 & Villa Bone-Kel. Roni & 16 \\
\hline 11 & $\begin{array}{l}\text { Rmh Keluarga Roni-rmh jl. } \\
\text { Merdeka }\end{array}$ & 190 \\
\hline 12 & $\begin{array}{l}\text { Bekas rumah E Couper-drg. } \\
\text { Budi Moniaga }\end{array}$ & 142 \\
\hline & Total jarak & 892 \\
\hline
\end{tabular}

Catatan: Cara penghitungan jarak dengan

menggunakan bantuan Google Earth

Berdasarkan rumus analisis tetangga terdekat, pola keletakan bangunan Indis yang berfungsi sebagai rumah tinggal di Kota Gorontalo dapat dihitung sebagai berikut:

$$
\begin{aligned}
\mathrm{Ju} & =\frac{0,89}{15} \\
& =0,06 \\
\mathrm{Jh} & =0,17 \\
\mathrm{~T} & =\underline{\mathrm{ju}} \\
& =\frac{0,06}{0,17}=0,35
\end{aligned}
$$

Dengan demikian pola keletakan bangunan Indis yang berfungsi sebagai rumah tinggal di Kota Gorontalo adalah berpola 
mengelompok, karena nilai $\mathrm{T}$ kurang dari 1.

Menurut Pacione dalam

Rangkuti (2000), faktor yang mempengaruhi pembentukan pola pemukiman mengelompok yaitu:
a. Faktor pertahanan menghadapi ancaman dari luar (eksternal).
b. Faktor ikatan keluarga atau turunan.
c. Faktor ketersediaan air (langka atau melimpah).
d. Faktor pembagian warisan (rumah dan tanah).
e. Faktor kegiatan ekonomi berbasis pertanian daripada ekonomi peternakan.
f. Faktor pertimbangan politis, religi atau ideologi.

Dari enam faktor yang mempengaruhi pola pemukiman mengelompok tersebut, faktor pertahanan dan pertimbangan politis, religi atau ideologis menjadi dasar pembentukan pola pemukiman Indis di Kota Gorontalo. Faktor pertahanan dapat diindikasikan dengan adanya markas polisi lapangan (veld politie) pada pintu masuk kawasan, dan polisi kota (stads politie) di tengah kawasan pemukiman.

\section{Bangunan sekolah}

Bangunan sekolah menyebar pada beberapa lokasi, namun tinggal dua yang masih bertahan dengan bangunan asli, yaitu bekas Holland Chinese School (SMAN 1) dan HIS (SDN 061). Bangunan ELS dan Schakel School sudah berubah dengan bangunan arsitektur jengki dan bangunan baru.Kedua bangunan letaknya berdekatan tidak terlalu jauh, tepatnya di Jalan $\mathrm{MH}$ Thamrin, Kelurahan Ipilo, Kecamatan Kota Timur.Pendirian sekolah pada masa penjajahan
Kolonial Belanda, dikarenakan perlunya sarana pendidikan bagi anak-anak pejabat dan pendatang yang berada di Kota Gorontalo.Kebutuhan pendidikan mendorong pemerintah kolonial Belanda mendirikan ELS (Europesche Lagere School), bagi kalangan Belanda dan Eropa, sedangkan HIS (Hollands Inlandsche School) diperuntukkan bagi golongan bangsawan pribumi.Masyarakat pendatang Cina mendirikan sekolah khusus bagi anak-anak mereka, yaitu HCS (Holland Chinese School). Jarak terdekat bangunan sekolah dapat dilihat pada tabel berikut ini:

Tabel 3. Jarak antar bangunan sekolah

\begin{tabular}{|r|l|r|}
\hline \multicolumn{1}{|c|}{ No } & Nama Bangunan & Jarak (m) \\
\hline \hline 1 & HCS-HIS & 201,6 \\
\hline 2 & HCS-ELS & 189 \\
\hline 3 & $\begin{array}{l}\text { SLS-Schakel } \\
\text { School }\end{array}$ & 636,5 \\
\hline \multicolumn{2}{|l|}{ Total jarak } \\
Catatan: Penghitungan jarak dengan menggunakan \\
Google Earth.
\end{tabular}

Pola keletakan bangunan sekolah dapat dihitung berdasarkan rumus analisis tetangga terdekat yaitu:

$$
\begin{aligned}
\mathrm{Ju} & =\frac{1,03}{4} \\
& =0,26 \\
\mathrm{Jh} & =0,17 \\
\mathrm{~T} & =\frac{\mathrm{ju}}{\mathrm{Jh}} \\
& =\frac{0,26}{0,17}=1,52
\end{aligned}
$$

Berdasarkan hasil penghitungan tersebut, maka pola keletakan bangunan sekolah adalah acak, karena nilai $T$ lebih besar dari 1 dan kurang dari 2,15. 


\section{Bangunan hotel dan gedung pertemuan.}

Letak bangunan hotel dan gedung pertemuan berada di sekitar lapangan (alun-alun), saat ini masuk dalam wilayah Kelurahan Tenda, Kecamatan Kota Selatan. Pendirian hotel di daerah ini, di karenakan lokasinya berdekatan dengan pusat kota dan pelabuhan. Hotel Melati (Velberg) awalnya merupakan hotel tempat menginap para awak kapal yang bersandar di Pelabuhan Gorontalo.Pelabuhan Gorontalo banyak disinggahi oleh kapal-kapal dagang semenjak masa VOC, bahkan pihak VOC mendirikan factorij (perwakilan dagang) di Kota Gorontalo pada tahun 1705 (Yayasan 23 Januari, 1942, 1982:25).Periode tahun 1920an1930an, Gorontalo banyak didatangi oleh warga asing untuk berdagang dan sekedar berkunjung (Amin, 2012:36-38). Hal ini tentunya membutuhkan tempat untuk menginap bagi pendatangpendatang tersebut. Selain hotel Melati (Velberg), terdapat hotel Gorontalo yang letaknya di sebelah Selatan lapangan (alun-alun). Jarak antar bangunan hotel dan tempat pertemuan dapat ditampilkan dalam tabel sebagai berikut :

Tabel 4. Jarak antar bangunan hotel dan tempat pertemuan

\begin{tabular}{|c|c|c|}
\hline No & Nama Bangunan & $\begin{array}{c}\text { Jara } \\
k(m)\end{array}$ \\
\hline 1 & $\begin{array}{l}\text { Hotel Gorontalo-Hotel } \\
\text { Velberg }\end{array}$ & 179 \\
\hline 2 & $\begin{array}{l}\text { Hotel Velberg-Societeit } \\
\text { Juliana }\end{array}$ & 165 \\
\hline 3 & $\begin{array}{l}\text { Sociteit Juliana-Hotel } \\
\text { Gorontalo }\end{array}$ & 91 \\
\hline & Total jarak & 435 \\
\hline
\end{tabular}

Berdasarkan rumus analisis tetangga terdekat, pola keletakan bangunan hotel dan tempat pertemuan dapat dihitung sebagai berikut :

$$
\begin{aligned}
\mathrm{Ju} & =\frac{0,43}{3} \\
\mathrm{Jh} & =0,14 \\
\mathrm{~T} & =0,17 \\
& =\frac{\mathrm{ju}}{\mathrm{Jh}} \\
& =\frac{0,14}{0,17}=0,85
\end{aligned}
$$

Dari hasil penghitungan tersebut dapat diketahui bahwa pola keletakan bangunan hotel dan tempat pertemuan di Kota Gorontalo adalah berpola mengelompok, karena nilai T kurang dari 1.

\section{B. Hubungan Antar Bangunan}

Penempatan pemukiman pada masa penjajahan kolonial Belanda di Kota Gorontalo, dipisahkan antara penguasa Belanda di pusat Kota dan sekitarnya, orang-orang Cina dan Arab di sekitar pasar, dan penduduk pribumi berada di tempat agak jauh dari pusat kota. Letak rumah penguasa dan pejabat Kolonial Belanda berada di pusat kota berdekatan dengan lapangan (alunalun). Model alun-alun yang berkembang sebagai prototipe identitas kota jaman kolonial terdapat pasar, serta daerah pertokoan yang terletak tidak jauh dari pusat pemerintahan (Handinoto, 2010:229). Pemilihan lokasi di sekitar lapangan (alun-alun) disebabkan mendekati pusat kota dan keramaian, selain itu akses jalan keluar (pelabuhan) tidak terlalu jauh dari lokasi. Secara umum, kota kolonial memiliki persamaan, yakni 
fakta bahwa mereka terbagi menjadi dua bagian, bagian yang berasal dari penduduk/budaya lokal dan bagian yang merupakan hasil dari cipta karya/budaya pendatang/orang asing. Campuran antara budaya lokal dan asing ini berakar pada sifat komunitas kolonial yang menekan, oleh karena hal ini, kota-kota kolonial sering kali dikarakterisasikan sebagai duality atau kota ganda (Murtomo, 2008:69).

Bangunan Indis di Kota Gorontalo mempunyai hubungan saling keterkaitan dalam penempatannya. Keletakan bangunan rumah tinggal di Kota Gorontalo terbagi dalam tiga kelompok, yaitu sekitar rumah Asisten Residen (kelurahan Biawao), Selatan lapangan (alun-alun), sekarang masuk wilayah kampung Tenda, dan sebelah Timur lapangan (alun-alun) masuk wilayah kelurahan Ipilo. Penempatan bangunan perumahan yang berada di sekitar rumah Asisten Residen diperkirakan merupakan perumahan bagi pejabatpejabat pemerintahan Kolonial Belanda dan pedagang kaya. Hal ini dapat dilihat dari kondisi bangunan yang lebih megah dibanding dengan bangunan di tempat lain. Hubungan keletakan bangunan rumah tinggal dan perkantoran, yang berdekatan dikarenakan agar jarak yang ditempuh tidak terlalu jauh. Bahkan terdapat beberapa rumah dinas yang lokasinya menyatu dengan kantor, seperti rumah dinas E. Balloom dan rumah dinas Kepala Kantor Pos. Menurut Turner dalam Ridwan Syah (2001) bahwa faktor yang berkaitan dengan efektivitas waktu tempuh seseorang dari tempat tinggal ke tempat bekerja merupakan alasan penting dalam pemilihan lokasi tinggal (Syah, 2001:22).
Kota Gorontalo mengalami perkembangan seiring dengan bertambahnya jumlah penduduk baik lokal maupun pendatang.Kawasan pemukiman yang awalnya berada di sekitar lapangan (alun-alun), berkembang ke arah utara (kelurahan Biawao dan Biawau sekarang ini) dan ke arah timur (kelurahan Ipilo sekarang ini). Menurut Branch (1995), unsur-unsur yang mempengaruhi perkembangan kota lebih mengacu kepada faktor internal atau situasi dan kondisi setempat, yaitu :

a. Keadaan geografis, merupakan pertimbangan yang esensial pada awal penentuan lokasi sebuah kota. Keadaan geografis ikut mempengaruhi fungsi dan bentuk kota. Kota yang berada di lokasi yang datar dapat berkembang secara merata ke segala arah.

b. Aspek tapak (site), mempengaruhi lokasi dan perubahan kota. Perubahan ruang kota sangat dipengaruhi oleh kemiringan lahan, keadaan geologis, dan fungsi yang diemban oleh kota itu.

c. Sejarah dan kebudayaan, mempengaruhi karakter fisik dan sifat-sifat kemasyarakatan kota. Lokasi bersejarah dan bangunanbangunan bersejarah menjadi pertimbangan untuk pengembangan kota (Branch, 1995:38-42).

Perubahan

ekspresi keruangan kota dipengaruhi oleh faktor fisik dan non fisik. Faktor fisik yang berpengaruh berkaitan dengan topografi, struktur geologi, geomorfologi, perairan dan tanah, faktor non fisik yang berpengaruh antara lain kegiatan penduduk (politik, sosial, budaya dan teknologi), urbanisasi, peningkatan kebutuhan akan ruang, peningkatan 
jumlah penduduk, perencanaan tata ruang, perencanaan tata kota, zoning, dan peraturan-peraturan pemerintah tentang bangunan (Yunus, 2002). Pada tahun 1942, pemukiman masyarakat Belanda berkembang di sebelah timur dan sebelah selatan lapangan (alunalun).Kemungkinan ini merupakan pemukiman Belanda dari golongan yang lebih rendah jabatannya. Hal ini dapat diindikasikan dari ukuran yang tidak terlalu besar serta bahan material dan hiasan ornamen yang tidak terlalu megah dibanding yang berada di sekitar rumah Asisten Residen (kelurahan Biawao).Selain itu juga terdapat rumah peristirahatan bagi bangsa Belanda. Hal ini dilihat dari adanya nama Villa Sweet Home dan Villa Bone pada kawasan tersebut.

Keletakan bangunan gereja berada di tengah-tengah antara kawasan rumah tinggal dan perkantoran dengan kawasan militer.Hal ini dimungkinkan agar jarak yang ditempuh tidak terlalu jauh, karena berada di tengahtengah wilayah.Bangunan gereja ini merupakan satu-satunya gereja yang ada pada masa itu, karena pihak penguasa lokal Gorontalo tidak mengizinkan penyebaran agama Kristen di Kota Gorontalo. Bangunan pertokoan terletak di dekat pasar yang merupakan pusat kegiatan perekonomian, di sebelah utara pusat kota berdekatan dengan kawasan Pecinan. Pemilihan lokasi bangunan pertokoan berdekatan dengan pasar bertujuan untuk memudahkan distribusi barang dan mudah dijangkau oleh seluruh lapisan masyarakat.

Keletakan bangunan sekolah yang acak, kemungkinan dimaksudkan untuk mendekati lokasi-lokasi pemukiman masyarakat dan tidak terpusat pada satu titik lokasi. Hal ini dapat dilihat dari lokasi keletakan bangunan Holland Chinese School dan HIS yang berada di sebelah timur, gedung ELS berada di sebelah utara kawasan, sedangkan Schakel School berada di sebelah barat kawasan.Berdasarkan lokasinya, peruntukan lahan bangunan di Kota Gorontalo pada masa penjajahan Kolonial Belanda dapat dikelompokkan menjadi ;

a. Bangunan perkantoran berada di pusat kota berdekatan dengan lapangan (alun-alun).

b. Bangunan rumah tempat tinggal pejabat berada di sekitar lokasi perkantoran, supaya mudah dan cepat sampai ke lokasi kantor.

c. Bangunan pemukiman Belanda yang lebih rendah pangkatnya berada di sebelah Timur dan Selatan (alun-alun).

d. Bangunan pertokoan berada dekat dengan pasar dan agak jauh dari lapangan (alun-alun), untuk memudahkan sirkulasi barang dagangan.

e. Bangunan hotel dan gedung pertemuan berada di sekitar lapangan (alun-alun).

f. Bangunan gereja (tempat ibadah) berada di tengah-tengah kawasan.

g. Bangunan pembangkit listrik berada di luar kota. Penempatan pembangkit listrik di luar kota dimaksudkan agar masyarakat tidak terganggu oleh suara mesin pembangkit.

h. Bangunan sekolah terletak menyebar dengan dimaksudkan agar tidak terlalu jauh dengan pemukiman penduduk. Gedung ELS berdekatan dengan pemukiman Belanda dan Eropa, HIS berdekatan dengan pemukiman penduduk lokal, dan HCSberdekatan dengan pemukiman Cina. 
i. Bangunan kantor polisi kota (stadspolitie) terletak di pusat kota, sedangkan kantor dan tangsi polisi lapangan (veld politie) berada di sebelah selatan dekat dengan pelabuhan.

j. Bangunan pemakaman Belanda saat ini sudah tidak ada lagi, menurut sumber Balai Pelestarian Cagar Budaya (BPCB) Gorontalo, dahulu terdapat pemakaman Belanda di belakang Kantor Dinas Kehutanan dan Pertambangan, namun saat ini sudah tidak terdapat sisanya, karena sudah terdapat bangunan baru (rumah) di atasnya.

\section{PENUTUP}

Pola penempatan bangunan Indis di Kota Gorontalo berpola mengelompok. Hal ini sesuai dengan hasil pengamatan di lapangan dengan penghitungan menggunakan metode analisis tetangga terdekat.Berdasarkan fungsi awalnya, hampir semua bangunan berpola mengelompok, kecuali bangunan perkantoran dan sekolah yang berpola acak.Pola acak pada bangunan sekolah dimungkinkan agar lokasinya merata tidak memusat pada satu lokasi, sehingga anak sekolah tidak terlalu jauh menjangkaunya. Pola keletakan bangunan Indis di Kota Gorontalo dapat dikelompokkan menjadi: Kelurahan Biawao, Kelurahan Tenda, dan Kelurahan Ipilo. Kelurahan Biawao kemungkinan merupakan kawasan pemukiman pejabat-pejabat Kolonial Belanda atau pedagang-pedagang besar Belanda.Hal ini dapat dilihat dari bangunan yang lebih besar dan megah dibandingkan di lokasi lainnya.

Hubungan antar bangunan indis di Kota Gorontalo saling terkait dalam penempatannya. Keletakan bangunan rumah tinggal di Kota Gorontalo terbagi dalam tiga kelompok, yaitu sekitar rumah Asisten Residen (kelurahan Biawao), Selatan lapangan (alun-alun), sekarang masuk wilayah kampung Tenda, dan sebelah Timur lapangan (alun-alun) masuk wilayah kelurahan Ipilo. Penempatan bangunan perumahan yang berada di sekitar rumah Asisten Residen diperkirakan merupakan perumahan bagi pejabatpejabat pemerintahan Kolonial Belanda dan pedagang kaya. Hubungan keletakan bangunan rumah tinggal dan perkantoran, berdekatan agar jarak yang ditempuh tidak terlalu jauh dan lebih cepat sampai ke kantor.Bangunan pertokoan berdekatan dengan pasar yang merupakan pusat kegiatan perekonomian untuk memudahkan sirkulasi

barang dagangan.Bangunan tempat ibadah terletak di tengah-tengah kawasan agar dapat mudah dijangkau dari semua lokasi.Lokasi bangunan sekolah terletak menyebar dengan maksud agar tidak terlalu jauh dari pemukiman penduduk. Gedung ELS berdekatan dengan pemukiman Belanda dan Eropa, HIS berdekatan dengan pemukiman penduduk lokal, dan HCS berdekatan dengan pemukiman Cina. 


\section{DAFTAR PUSTAKA}

Amin, Basri. 2012. Memori Gorontalo, Teritori, transisi dan tradisi, Yogyakarta : Penerbit Ombak.

Antariksa. 2010. Tipologi Wajah Bangunan dan Riasan dalam Arsitektur Kolonial Belanda, www. antariksaarticle.blogspot.com, diunduh tanggal 27 Oktober 2011.

Apriyanto, Djoni. 2006. Historiografi Gorontalo, Konflik Gorontalo-Hindia Belanda Periode 1856-1942. Gorontalo : Universitas Negeri Gorontalo Press.

Bintarto dan Hadisumarno. 1982. Metode Analisis Geografi, Yogyakarta : Gadjah Mada University Press.

Branch, C. Melville. 1995. Perencanaan Kota Komprehensif(Pengantar dan Penjelasan), diterjemahkan oleh Bambang Hari Wibisono dan Achmad Djunaedi, Yogyakarta : Gadjah Mada University Press.

Gunadi dan Tri Hatmaji.1997. "Kelestarian dan pelestarian Bangunan Indis di Jawa Tengah," Makalah DIA VIII, Yogyakarta, halaman 1-11.

Handinoto. 2010."Perubahan Besar Morpologi Kota-Kota di Jawa pada Awal dan Akhir Abad ke-20", dalam Arsitektur dan Kota-kota di Jawa pada Masa Kolonial, Yogyakarta : Grha Ilmu.

Hastati, Fauza. 2003. "Karakteristik Arsitektural Bangunan Indis Pada Perumahan Pegawai Perusahaan Jawatan Kereta Api Pengok Blok A dan Blok B di Yogyakarta", Tesis, Yogyakarta : Teknik Arsitektur Universitas Gadjah Mada.

Martono, Agus Dwi. 1996. "Kajian Pola Persebaran Permukiman di Kabupaten Klaten Propinsi Jawa Tengah", Tesis, S2 Geografi Universitas Gadjah Mada : Yogyakarta.

Rangkuti, Nurhadi. 2000. "Situs Permukiman Bonang di Lasem : Tinjauan Khusus Tentang Pola, Struktur dan Proses Keruangannya", Tesis, S2 Geografi Yogyakarta : Universitas Gadjah Mada.

Soekiman, Djoko.2011. Kebudayaan Indis dari Zaman Kompeni sampai Revolusi, Jakarta : Komunitas Bambu.

Syah, Ridwan. 2001. "Struktur dan Pola Spasial Kawasan Senggigi dan Sekitarnya", Tesis, Magister Perencanaan kota dan Daerah, Yogyakarta : Universitas Gadjah Mada.

Tanudirdjo, Daud Aris. 1989. "Ragam Metode Penelitian Arkeologi dalam Skripsi Karya Mahasiswa Arkeologi Universitas Gadjah Mada" Laporan Penelitian, Yogyakarta : Fakultas Sastra Universitas Gadjah 
Tim. 2008. Metode Penelitian Arkeologi, Jakarta : Pusat Penelitian dan Pengembangan Arkeologi Nasional.

Wahyuhono, Bambang Prasetyo dan Tri Hartono.1997. "Bangunan-bangunan Indis di Yogyakarta Tinjauan Kelestarian dan Pelestariannya", Makalah DIA VIII, Yogyakarta, halaman 1-11.

Wiyatiningsih. 2000. "Kajian Karakteristik Arsitektural Bangunan Peninggalan Masa Kolonial Belanda di Bintaran Yogyakarta", Tesis, S2 Teknik Arsitektur Yogyakarta : Universitas Gadjah Mada.

Yayasan 23 Januari 1942. 1982. Menentang Kolonialisme dan Mempertahankan Negara Proklamasi, Gorontalo : Yayasan 23 Januari 1942 bekerja sama dengan IKIP Manado Cabang Gorontalo.

Yunus, Hadi Sabari. 2005. Manajemen Kota Perspektif Spasial, Yogyakarta : Pustaka Pelajar. 
